\title{
PELAKSANAAN FUNGSI PENGAWASAN DEWAN PENGAWAS SYARIAH PADA BANK SYARIAH DI KOTA MAKASSAR
}

\author{
The Implementation of the Supervisory Function for Sharia Supervisory Board at Sharia Banks in \\ Makassar City
}

\author{
Abdurrahman $^{1}$, Baso Madiong $^{2}$, Zulkifli Makkawaru $^{2}$ \\ ${ }^{1}$ Magister Ilmu Hukum Program Pascasarjana Universitas Bosowa \\ ${ }^{2}$ Program Studi Ilmu Hukum Program Pascasarjana Universitas Bosowa \\ Email: rahmandm20@gmail.com
}

Diterima: 01 Agustus 2020/Disetujui: 07 Desember 2020

\begin{abstract}
ABSTRAK
Penelitian ini bertujuan untuk mengetahui pelaksanaan fungsi pengawasan Dewan Pengawas Syaraiah (DPS) pada bank syariah serta kendala yang dihadapi DPS dalam melaksanakan fungsi pengawasan pada bank syariah. Jenis penelitian yang digunakan adalah penelitian deskriptif dengan pendekatan kualitatif. Lokasi penelitian di Unit Usaha Syariah (UUS) Bank Sulselbar yang berada di Kota Makassar. Responden penelitian ini adalah anggota DPS di UUS Bank Sulselbar. Metode pengumpulan data menggunakan teknik wawancara dan kepustakaan. Hasil penelitian menunjukan bahwa pelaksanaan fungsi pengawasan DPS di UUS Bank Sulselbar telah cukup optimal. Bentuk pengawasan DPS terdiri dari pengawasan onsite (pengawasan langsung) dan off-site (pengawasan tidak langsung). Pengawasan DPS meliputi; menganalisa laporan hasil audit internal dan fungsi kepatuhan untuk pemenuhan prinsip-prinsip syariah atas kegiatan penghimpunan dana dan penyaluran dana serta pelayanan jasa bank, melakukan uji petik, memberikan saran dan opini syariah, melaksanakan rapat dan kajian internal, serta membuat laporan pengawasan secara periodik. Adapun kendala pelaksanaan fungsi pengawasan DPS yakni kurangnya sumber daya insani (SDI) di bank syariah, serta belum maksimalnya penerapan Good Coorporate Governance (GCG) oleh DPS.
\end{abstract}

Kata Kunci: Pengawasan, Dewan Pengawas Syariah, Bank Syariah, Unit Usaha Syariah, Bank SulSelBar

\begin{abstract}
This study aims to determine the implementation of the supervisory function of Sharia Supervisory Board (DPS) in Islamic banks as well as the obstacles faced by DPS in carrying out the supervisory function in Islamic banks. This type of research is a descriptive study with a qualitative approach. The location of the study is in the Sulselbar Bank Syariah Business Unit (UUS) located in Makassar City. The respondents of this study were DPS members at the Sulselbar Bank UUS. Data collection methods using interview techniques and literature. The results of the study showed that the implementation of the DPS supervision function at UUS Bank Sulselbar was quite optimal. The form of DPS supervision consists of on-site supervision (direct supervision) and off-site (indirect supervision). Supervision of SSB includes; analyzing reports on the results of internal audit and compliance functions to fulfill sharia principles for fundraising and distribution of funds and bank services, conducting sampling tests, providing sharia advice and opinions, conducting internal meetings and studies, and making periodic monitoring reports. The obstacles to the implementation of the supervisory function of the DPS are a lack of human resources (SDI) in Islamic banks, and not yet the maximum implementation of Good Corporate Governance (GCG) by DPS.
\end{abstract}

\section{Keywords: Supervision, Sharia Supervisory Board, Sharia Bank, Syariah Business Unit, Sulselbar Bank}

\section{PENDAHULUAN}

Kehadiran perbankan syariah berawal dari harapan masyarakat Muslim agar tersedianya lembaga keuangan yang berlandaskan etika, nilai moral, dan prinsip-prinsip syariah (Amiruddin, 2011). Khususnya, keinginan untuk menghindari praktik riba (penambahan/bunga), gharar (spekulasi), dan maisir (ketidakjelasan) dalam aktivitas ekonomi sehari-hari. Hal ini kemudian direspon positif oleh kalangan ulama dan ekonom Muslim yang akhirnya melahirkan serta mengembangkan berbagai bentuk lembaga keuangan berbasis syariah.

Pesatnya perkembangan bank syariah di dunia dapat dilihat dari laporan bertajuk Islamic Finance Development Report 2018 yang dipublikasikan oleh Thomson Reuters, dalam laporan tersebut diketahui bahwa tiap tahunnya rata-rata pertumbuhan asset keuangan syariah secara global bertumbuh $8,16 \%$ dalam periode 2014 - 2017. Jika 
pada tahun 2014, total aset keuangan syariah berada di angka US\$ 1,96 triliun, nilainya melonjak menjadi US\$ 2,24 triliun pada tahun 2017. Bahkan Reuters memproyeksikan pada tahun 2023, total nilai aset keuangan syariah global bisa mencapai angka US\$ 3,81 triliun. Dari jumlah aset keuangan syariah global tersebut, $71 \%$ merupakan aset perbankan syariah, yakni di angka US\$ 1,73 triliun.

Sedangkan pertumbuhan bank syariah di Indonesia, berdasarkan data statistik perbankan syariah yang diterbitkan Otoritas Jasa Keuangan (OJK) pada periode Juni 2018 yakni, jumlah Bank Umum Syariah (BUS) sebanyak 13 institusi dengan jumlah kantor sebanyak 1.827 unit dan total aset sebesar Rp. 294,30 triliun, Unit Usaha Syariah (UUS) sebanyak 21 institusi dengan jumlah kantor sebanyak 349 unit dan total aset sebesar Rp. 138,88 triliun, sedangkan Bank Pembiayaan Rakyat Syariah (BPRS) sebanyak 168 institusi dengan jumlah kantor 459 unit dan total aset Rp. 11,24 triliun. Tentunya, angka pertumbuhan dan perkembangan yang menggembirakan ini harus diikuti dengan sistem regulasi dan pengawasan yang memadai.

Untuk menjamin bank syariah dalam menjalankan aktivitasnya tetap memenuhi kewajiban menjaga kepatuhan dan kesesuaian terhadap prinsip-prinsip syariah, maka dibutuhkan sebuah lembaga independen yang memiliki kapasitas dan integritas dibidang syariah, ekonomi, serta perbankan untuk mengawasi perbankan syariah. Di Indonesia, lembaga pengawas syariah wajib dimiliki oleh setiap perseroan yang menjalankan kegiatan usaha berdasarkan prinsip syariah, termasuk industri perbankan. Lembaga pengawas tersebut dikenal dengan nama Dewan Pengawas Syariah (DPS) yang bertugas memberikan nasehat dan saran kepada direksi serta mengawasi kegiatan perseroan agar sesuai dengan prinsip syariah. Hal ini sebagaimana tercantum dalam Pasal 109 Undang-Undang RI Nomor. 40 tahun 2007 tentang Perseroan Terbatas dan Pasal 32 Undang-Undang RI Nomor. 21 tahun 2008 tentang Perbankan Syariah.

Kehadiran bank syariah dan DPS dalam sistem ekonomi Indonesia bukannya tanpa masalah dan kritik. Berbagai kasus terkait kinerja dan aspek kepatuhan terhadap prinsip-prinsip syariah sering terjadi. Contoh kasus yang terjadi yakni, kasus kredit sidikasi Proyek Indosat Multimedia Mobil (IM3) yang melibatkan beberapa bank atau unit usaha syariah seperti Bank Syariah Mandiri (BSM) dan BNI Divisi Usaha Syariah yang mengikuti kredit sindikasi tersebut, serta akan memperoleh bunga atas pembiayaan tersebut $19 \%$ per tahun (Republika, 8/8/2002). Laporan BI mengatakan bahwa beberapa bank syariah sempat mengikuti kredit sindikasi tersebut yang menggunakan sistem bunga. Setelah dikonfirmasi pihak bank beralasan bahwa hal tersebut terpaksa dilakukan dengan makna darurat (Arifain, at.al, 2021).

Kasus lainnya adalah kasus gadai emas perbankan syariah yang mendapatkan perhatian khusus dari Bank Indonesia (BI) karena dinilai tidak memenuhi prinsipprinsip syariah dan berujung pada spekulasi dalam produk gadai emas (Badruddin, 2014). Kasus investasi emas PT Golden Traders Indonesia Syariah (GTIS) yang gagal bayar dan menggelapkan dana nasabah ini, turut melibatkan MUI yang menerbitkan sertifikat halal terhadap skema investasi GTIS. Selain itu, Yayasan Dana
Dakwah Pembangunan milik MUI turut menerima keuntungan saham sebesar $10 \%$ dari PT GTIS karena pengurus MUI menjabat sebagai Dewan Pengawas Syariah di PT GTIS. Menurut Adiwarman (2004), Penetapan nisbah bagi hasil keuntungan ditentukan berdasarkan pada perkiraan keuntungan yang diperoleh nasabah/mudharib dibagi dengan referensi tingkat keuntungan yang telah ditetapkan. Sedangkan penentuan nisbah bagi hasil berdasarkan pendapatan ditentukan dengan perkiraan pendapatan yang diperoleh nasabah dibagi dengan referensi tingkat keuntungan yang telah ditetapkan.

Hasil penelitian Bank Indonesia bekerjasama dengan Ernst \& Young (2008) sebagaimana dikutip oleh Agustianto, menyimpulkan bahwa peran DPS belum optimal. Dilanggarnya syariah compliance akibat lemahnya pengawasan DPS memiliki dampak risk manajemen. Jenis manajemen resiko yang terkait erat dengan DPS adalah resiko reputasi yang selanjutnya berdampak pada displaced commercial risk, seperti resiko likuiditas dan resiko lainnya (Didin \& hendri, 2003).

Faisal (2003), menyatakan bahwa masalah-masalah yang timbul berkaitan dengan aspek kepatuhan syariah pada perbankan syariah, kemudian menimbulkan keraguan dan pertanyaan masyarakat terkait kinerja dan profesionalitas DPS dalam melaksanakan fungsi pengawasan di perbankan syariah. Bahkan, sebagian masyarakat menganggap bank-bank syariah tidak ada bedanya dengan bank-bank konvensional yang menggunakan sistem bunga. Hal ini tentu saja menjadi persoalan serius yang harus dijawab oleh semua pihak yang berkepentingan dalam industri keuangan syariah di Indonesia, khususnya perbankan syariah.

Tujuan penelitian ini adalah: (1) untuk mengetahui pelaksanaan fungsi pengawasan dewan pengawas syariah pada bank syariah, khususnya yang berada di Kota Makassar, (2) untuk mengatahui kendala atau hambatan yang dihadapi dewan pengawas syariah terkait pelaksanaan fungsi pengawasannya pada bank syariah.

\section{METODE}

\subsection{Tipe Penelitian}

Jenis penelitian ini adalah jenis penelitian hukum yang bersifat deskriptif dengan pendekatan kualitatif. Penelitian deskriptif adalah penelitian yang berusaha mendeskripsikan suatu gejala, peristiwa, kejadian yang terjadi saat sekarang. Penelitian deskriptif memusatkan perhatian kepada masalahmasalah aktual sebagaimana adanya pada saat penelitian berlangsung. Melalui penelitian deskriptif, peneliti berusaha mendeskripsikan peristiwa dan kejadian yang menjadi pusat perhatian (Suratman dan Philips, 2004)

\subsection{Jenis dan Sumber Data}

Sumber data adalah tempat dimana dapat diketemukannya data-data penelitian. Jenis Data yang digunakan dalam penelitian ini ada dua, yakni; (1) Data Primer, yaitu data yang diperoleh langsung saat penelitian seperti, data dari hasil wawancara dengan anggota DPS pada bank syariah yang telah ditentukan serta, pihak-pihak yang terkait dengan fungsi pengawasan bank syariah di Indonesia. (2) Data Sekunder, yaitu data yang sudah ada dan tersedia, baik yang diperoleh dari bank syariah, DSN-MUI, BI, dan OJK, maupun data dari lembaga lain yang dinilai perlu dan berkaitan dengan penelitian. 


\subsection{Teknik Pengumpulan Data}

Cara untuk mengumpulkan data, peneliti lakukan dengan teknik sebagai berikut; (1) Teknik Wawancara (interview), yaitu melakukan tanya jawab secara langsung dan mendalam dengan responden/narasumber yang telah ditentukan, dalam hal ini menggunakan teknik wawancara mendalam (indeep interview). (2) Teknik Kepustakaan, yaitu suatu teknik penelaahan normatif dari beberapa data-data dan dokumen yang telah ada, peraturan perundang-undangan terkait, serta penelahaan beberapa literatur yang relevan penelitian ini.

\section{HASIL DAN PEMBAHASAN}

\subsection{Pelaksanaan Fungsi Pengawasan DPS Pada UUS Bank Sulselbar}

Menurut Mukhlis Sufri dan Abdul Gaffar Lewa, dalam melaksanakan fungsi pengawasan sebagai anggota DPS di UUS Bank Sulselbar terbagi dalam 2 bentuk atau model pengawasan yakni sebagai berikut:

1. Pengawasan On-Site yakni; pengawasan langsung yang dilakukan oleh DPS dengan turun langsung meninjau aktivitas operasional di Bank untuk memastikan terpenuhinya aspek kepatuhan syariah dan mengidentifikasikan permasalahan yang menjadi temuan.

2. Pengawasan Off-Site yakni; pengawasan tidak langsung yang dilakukan oleh DPS dengan menganalis laporanlaporan dan data-data terkait kegiatan operasional bank, tanpa harus meninjau langsung aktivitas operasional bank.

Kedua bentuk pengawasan tersebut, menurut peneliti telah sesuai dengan Peraturan Bank Indonesia Nomor 11/33/PBI/2009 tentang Pelaksanaan Good Coorporate Governance bagi Bank Umum Syariah dan Unit Usaha Syariah, serta memenuhi kriteria pedoman pelaksanaan GCG yang tercantum dalam Surat Edaran Bank Indonesia (SEBI) Nomor 12/13/DPbS tertangal 30 April 2010 perihal Pelaksanaan Good Coorporate Governance bagi Bank Umum Syariah dan Unit Usaha Syariah. Selain itu, bentuk pelaksanaan pengawasan DPS tersebut telah sesuai dengan Pedoman Kerja dan Tata Tertib DPS di UUS Bank Sulselbar.

Dewan Pengawas Syariah (DPS) di UUS Bank Sulselbar telah memiliki Pedoman Kerja dan Tata Tertip yang dibuat dalam rangka melaksanakan tugas dan tanggung jawabnya sebagai DPS, termasuk pelaksanaan fungsi pengawasan. Menurut Mukhlis Sufri dan Abdul Gaffar Lewa, dengan adanya pedoman kerja dan tata tertip tersebut diharapkan mampu meningkatkan efektivitas pelaksanaan tugas dan tanggung jawab DPS, khususnya dalam mengawasi aktivitas operasional UUS Bank Sulselbar agar tetap mematuhi aspek syariah. Pedoman kerja dan tatip juga dibutuhkan dalam rangka penguatan kelembagaan DPS.

Menurut Kamal Ikbal Monoarfa yang merupakan staf analis di Gorup UUS Bank Sulselbar, intensitas kehadiran DPS di kantor UUS Bank Sulselbar telah cukup baik yakni minimal 2 kali dalam seminggu. Sedangkan, rapat DPS dilaksanakan minimal 1 kali dalam sebulan.

Adapun pelaksanaan fungsi pengawasan DPS di UUS Bank Sulselbar yakni sebagai berikut:

1. Menganalisa Laporan hasil audit internal dan fungsi kepatuhan untuk pemenuhan prinsip-prinsip syariah atas kegiatan penghimpunan dana dan penyaluran dana serta pelayanan jasa bank, dan memberikan pendapat bahwa kaidah kaidah Syariah telah terpenuhi pada kegiatan Penghimpunan Dana dan Penyaluran Dana.

2. Mengambil uji petik dari Kantor Cabang Syariah untuk memperhatikan kualitas pelaksanaan pemenuhan terhadap akad akad pembiayaan an. Ashary Thahir Ramly No Akad 01 tangggal 06 November 2018, an. Syamsuddin Akad No.16 tanggal 25 Oktober 2018, an. Nurhana Akad No.12 tanggal 17 Juli 2018, dan Akad Nurhayati No.20 tanggal 17 Juli 2018 bahwa akad tersebut telah sesuai dengan Prinsip-Prinsip Syariah.

3. Melakukan Review terhadap SOP terkait aspek-aspek Syariah.

4. Memberikan pendapat Syariah atas SOP-BPP terkait aspek-aspek Syariah.

5. Memberikan tanggapan terhadap Hasil Pemeriksaan OJK.

6. Memberikan kajian HUKUM dan pengelolaan ZAKAT terhadap BABINROHIS.

7. Menganalisa hasil kajian tentang Pembiayaan Modal Kerja Musyarakah Mutanaqisah (MMQ) dan Internet Banking.

8. Melaporkan Hasil pengawasan Dewan Pengawas Syariah ke Direksi dan Komisaris sebagai Supervisi Grup Unit Usaha Syariah Bank Sulselbar.

Menurut Abdul Gaffar Lewa, dalam melaksanakan fungsi pengawasannya, DPS di UUS Bank Sulselbar senantiasa melakukan komunikasi dan koordinasi secara intensif dengan pihak manajemen Group UUS dan pengurus kantor cabang UUS, baik yang ada di kota Makassar maupun di daerah lainnya.

Untuk pelaporan hasil pengawasan, DPS di UUS Bank Sulselbar telah melaksanakan laporan hasil pengawasan secara rutin (berkala) yakni 2 kali dalam setahun (per semester). Laporan pengawasan DPS tersebut harus mengikuti pedoman pelaporan hasil pengawasan DPS yang dikeluarkan oleh OJK. Laporan tersebut sangat penting, karena nantinya akan digunakan sebagai bahan penilaian, evaluasi, serta rujukan bagi OJK, DSN-MUI, maupun bagi Direksi dan RUPS bank Sulselbar.

Sedangkan, untuk kebijakan remunerasi DPS Bank Sulselbar, telah tertuang dalam Keputusan Direksi No. SK/062/DIR/IV/2018 tangal 11 April 2018 tentang Penyesuaian Honorarium Ketua dan Anggota Dewan Pengawas Syariah, serta Anggota Komite Dewan Komisaris Bank Sulselbar yakni sebagai berikut:

a. Ketua DPS mendapatkan honorarium sebesar Rp. 11.000.000 (sebelas juta rupiah) per bulan. Sedangkan, Anggota mendapatkan honorarium sebesar Rp. 10.000.000 (sepuluh juta rupiah) per bulan.

b. Kedua anggota DPS menerima remunerasi per orang dalam setahun sebesar Rp. 500 Juta ke bawah.

Selain itu, DPS di UUS Bank Sulselbar juga menerima fasilitas-fasilitas penunjang lainnya sesuai dengan SK Pengangkatan DPS yakni sebagai berikut:

a. Ruang kerja yang memadai

b. Staf khusus untuk membantu pelaksanaan tugas DPS

c. Mendapatkan biaya transportasi

d. Mendapatkan biaya asuransi kesehatan dan asuransi jiwa.

Menurut Mukhlis Sufri, masih banyak hal yang mesti diperbaiki dan ditingkatkan dalam melaksanakan fungsi 
pengawasan DPS di UUS Bank Sulselbar. Hal ini dikarenakan perkembangan perbankan dan persoalan-persoalan terkait aspek kepatuhan syariah yang cukup dinamis dan membutuhkan respon yang cepat dan tepat untuk menjawabnya.

\subsection{Kendala Pelaksanaan Fungsi Pengawasan DPS Pada UUS Bank Sulselbar}

Menurut Didin Hafidhudhin (2003), bahwasannya secara umum kendala perbankan syariah saat ini yakni kurangnya tenaga DPS yang berkualitas. Dimana para ulama, kyai, dan ustadz yang memahami secara baik ilmu agama sekaligus paham ilmu ekonomi dan perbankan syariah masih sangat minim, sehingga banyak angggota DPS hanya terdapat di bank-bank besar di kantor pusat, sedangkan di daerah masih sangat kekurangan. Sumber daya manusia perbankan syariah juga belum banyak memadai. Hal ini dikarenakan banyak pimpinan-pimpinan bank syariah yang diambil dari bank konvensional. Sehingga, perlu waktu untuk belajar serta menyesuaikan pola fikir dan pola kerja yang sesuai dengan prinsip syariah. Termasuk kekurangan sumber daya manusia di tingkat karyawan itu sendiri, masih banyak yang bukan berlatarbelakang ekonomi syariah atau perbankan syariah.

Berdasarkan hasil penelitian, peneliti dapat mengidentifikasikan beberapa hal yang menjadi kendala dari pelaksanaan fungsi pengawasan DPS pada UUS Bank Sulselbar, yakni sebagai berikut:

1. Kurangnya Sumber Daya Insani (SDI)

Salah satu kedala dari pelaksanaan fungsi pengawasan DPS pada UUS Bank Sulselbar yakni kurangnya ketersedian sumber daya Insani (SDI) yang memiliki kapasitas dan kapabilitas yang mumpuni, baik dibidang ekonomi syariah, akutansi syariah, maupun perbankan syariah yang dapat mengelola bank syariah secara professional, baik di tingkat karyawan, manajemen, direksi maupun pimpinan di bank syariah.

Sebagaimana diungkapkan Mukhlis Sufri, bahwasannya salah satu kendala perbankan syariah saat ini yakni kurangnya sumber daya manusia yang benar-benar memahami konsep ekonomi syariah maupun perbankan syariah yang dapat direkrut menjadi pegawai bank syariah. Hal ini juga disebabkan karena belum maksimalnya sosialisasi tentang ekonomi syariah dan industri keuangan syariah sehingga minat masyarakat mempelajari ekonomi syariah, akutansi syariah, maupun perbankan syariah juga masih sangat minim.

Hal ini juga ditegaskan oleh Abdul Gaffar Lewa yang menyatakan bahwa, salah satu tantangan dalam pengembangan perbankan syariah serta pelaksanaan fungsi pengawasan DPS adalah keterbatasan sumber daya insani (SDI) yang memahami konsep ekonomi syariah dan tata kelola perbankan syariah.

2. Belum Maksimalnya Penerapan Good Coorporate Governance (GCG) dan Pelaksanaan Pedoman Kerja serta Tata Tertip oleh DPS

Menurut Supiana Saputri, salah seorang Pengawas Bank Syariah dari Otoritas Jasa Keuangan (OJK) Kantor Regional VI Sulawesi, Maluku dan Papua (Sulampapua) mengungkapkan bahwa, kendala yang dihadapi DPS di Bank Syariah khususnya di Kota Makassar, umumnya disebabkan karena belum maksimalnya penerapan GCG oleh DPS maupun bank syariah itu sendiri. Sehingga, potensi untuk munculnya masalah dan penyimpangan terhadap aspek syariah cukup mengkhawatirkan.
Selain itu, Supiana Saputri juga menjelaskan bahwasannya OJK hingga saat ini belum memiliki kewenangan untuk memberikan sanksi bagi DPS yang tidak melaksanakan tugas dan fungsinya. OJK hanya dapat memberikan rekomendasi kepada pihak Bank atau RUPS jika menemukan adanya DPS yang tidak bekerja secara profesional dan akuntabel.

Berdasarkan hasil wawancara dengan anggota DPS di UUS Bank Sulselbar, peneliti menyimpulkan bahwa kendala yang masih sering terjadi adalah kurang maksimalnya penerapan GCG oleh DPS. Hal ini dikarenakan pedoman kerja dan tata tertib DPS Bank Sulselbar belum terperinci dan optimal menyerap ketentuan-ketentuan terkait GCG yang tercantum dalam Peraturan Bank Indonesia Nomor 11/33/PBI/2009 tentang Pelaksanaan Good Coorporate Governance bagi Bank Umum Syariah dan Unit Usaha Syariah, serta pedoman pelaksanaan GCG yang tercantum dalam Surat Edaran Bank Indonesia (SEBI) Nomor 12/13/DPbS tertangal 30 April 2010 perihal Pelaksanaan Good Coorporate Governance bagi Bank Umum Syariah dan Unit Usaha Syariah.

Peneliti juga menilai perlu adanya aturan khusus yang mengatur tentang pedoman pelaksanaan tugas dan fungsi DPS yang lebih spesifik dan berlaku secara umum. Hal ini sangat diperlukan, untuk menggantikan Peraturan Bank Indonesia Nomor 11/33/PBI/2009 tentang Pelaksanaan Good Coorporate Governance bagi Bank Umum Syariah dan Unit Usaha Syariah.

Selain itu, berdasarkan hasil penelitian, diharapkan adanya organisasi yang mewadahi seluruh anggota DPS di seluruh Indonesia, yakni organisasi khusus profesi DPS yang mencakup seluruh industri keuangan syariah. Hal ini diperlukan untuk penguatan profesi dan kelembagaan DPS, serta dapat bagi para DPS bertukar informasi, pengalaman dan gagasan dalam rangka mengembangkan ekonomi syariah dan industry keuangan syariah di Indonesia.

\section{KESIMPULAN DAN SARAN}

Berdasarkan hasil penelitian terkait Pelaksanaan Fungsi Pengawasan Dewan Pengawas Syariah Pada Bank Syariah di Kota Makassar, yakni pada Unit Usaha Syariah (UUS) Bank Sulselbar, maka penulis dapat menarik kesimpulan bahwa pelaksanaan fungsi pengawasan Dewan Pengawas Syariah (DPS) di UUS Bank Sulselbar telah cukup optimal. Pengawasan DPS dilaksanakan dengan dua bentuk yakni pengawasan on-site (pengawasan langsung) dan off-site (pengawasan tidak langsung). Pengawasan DPS tersebut meliputi; menganalisa laporan hasil audit internal dan fungsi kepatuhan untuk pemenuhan prinsip-prinsip syariah atas kegiatan penghimpunan dana dan penyaluran dana serta pelayanan jasa bank, melakukan uji petik, memberikan saran dan opini syariah, melaksanakan rapat dan kajian internal, serta membuat laporan pengawasan secara periodik. Kendala pelaksanaan fungsi pengawasan DPS pada UUS Bank Sulselbar yakni; kurangnya ketersedian sumber daya Insani (SDI) dibidang ekonomi syariah, akutansi syariah, maupun perbankan syariah, baik di tingkat karyawan, manajemen, direksi maupun pimpinan di bank syariah. Serta, belum maksimalnya penerapan Good Coorporate Governance (GCG) oleh DPS. 


\section{DAFTAR PUSTAKA}

A. Adiwarman Karim. 2004. Bank Islam; Analisis Fiqih dan Keuangan. PT RajaGrafindo Persada, Jakarta.

Amiruddin Kadir. 2011. Ekonomi dan Keuangan Syariah. Alauddin University Pers, Makassar.

Arifain, M., Siku, A. S., \& Hamid, A. H. (2021). Fungsi Pengawasan Ombudsman Terhadap Pelaksanaan Tata Kelola Administrasi Di Pengadilan Negeri Mamuju. Indonesian Journal of Legality of Law, 2(2), 113-121. https://doi.org/10.35965/ijlf.v2i2.468

Badrudin. 2014. Dasar-Dasar Manajemen. Alfabeta, Bandung.

Didin Hafiduddin dan Hendri Tanjung. 2003. Manajemen Syariah dalam Praktek. Gema Insani Press, Jakarta.

Ernst \& Young. 2008. Detecting Financial Statement Fraud: What Every Manager Needs to Know.

Faisal Badroen.,et.al. 2006. Etika Bisnis dalam Islam. Kencana, Jakarta.

M. Arfin Hamid. 2007. Hukum Ekonomi Islam (Ekonomi Syariah) Di Indonesia; Aplikasi dan Prespektifnya. Ghalia Indonesia, Bogor.

M. Manullang. 2012. Dasar-Dasar Manajemen. Gajah Mada University Press, Yogyakarta.

Mardani. 2011. Hukum Ekonomi Syari'ah di Indonesia. Refika Aditama, Bandung.

Muhammad Syafi'i Antonio. 2001. .Bank Syariah dari Teori

Muhammad. 2011. Manajemen Bank Syariah, Edisi Revisi Kedua. UPP-STIM YKPN, Yogyakarta.

Suratman dan Philips Dillah. 2014. Metode Penelitian Hukum. Alfabeta, Bandung. 